\title{
LA DOCTRINA DE LOS ACTOS PROPIOS EN EL DERECHO CIVIL PERUANO
}

René Ortiz Caballero

\section{INTRODUCCION}

La buena fe es un principio general del Derecho cuya imprecisa y discutible conceptualización ha hecho dudar de su juridicidad. Quienes recusan su naturaleza técnico-jurídica han visto en ella en la buena fe- la puerta por la cual se deslizan la ética o, más ampliamente, la moral, en grave perjuicio de la ciencia jurídica. Esto es así, en primer lugar, porque la disciplina juridica pretende ser, precisamente, una ciencia, es decir, un conjunto sistemático de regulaciones racionales y completas en sí mismas y, en todo caso, perfectible ejercitando su propia lógica resolutivo-compositiva. La ética tiene dos rasgos que se concilian difícilmente con el tipo de ciencia descrito; en primer lugar, sigue siendo una rama de la Filosofía y, como tal, su modo de conocer no permite arribar a un conjunto de verdades hic et nunc, sino a una sabiduría conformada por verdades siempre en cuestión, de tal suerte que no se agota en sí misma sino que está en natural disposición para incorporar nuevos contenidos.

Un tipo de conocimien to como éste, impreciso e inseguro, aun en un momento determinado, no es el más adecuado para tratar racionalmente los fenómenos interpersonales, con vistas a la certeza jurídica.

En segundo lugar, el campo donde suele discurrir la ética para discernir lo bueno de lo malo está en el interior del hombre; este campo, por sí mismo, es arduamente asimilable a la perspectiva fenoménica que suele caracterizar al campo de lo jurídico. La buena fe reúne dos términos internos prima facie: la fe, que en buena medida es una creencia sustentada en la confianza en algo o alguien 
-y no en el conocimiento-, y el bien, concepto plurisignificante (ente, propiedad del ente o valor) cuyo alcance suele oscilar, amén de otras posibilidades, dentro de una perspectiva de bien moral, entre un bien subjetivo, determinable por el juicio individual, y otro material u objetivo, ubicable en las cosas concretas.

Sea como fuere, la buena fe se nos presenta, en este orden de ideas no jurídico, como la creencia en el actuar propio o ajeno que es correcto o, en términos kantianos, deseable por todos siempre y al mismo tiempo.

Abierta así la puerta del Derecho a la ética, o a la moral, con todo lo de desintegrante que tiene para el legalismo lógico-formal, nos encontramos con posiciones, como la de Diez-Picazo, que nos sitúa la ética, admitida que sea, no como una material u objetiva, sino como una práctica o situacional. Esto implica variabilidad de criterios pero no en función de las convicciones imperantes en la comunidad sino en "referencia a casos de conflicto que son propios del mundo del Derecho y en alguna medida típicos" (Wieacker $1977: 15$ ).

Siguiendo este horizonte, uno de los criterios que parece llevar a predios jurídicos el concepto de buena fe es el de la doctrina de los actos propios. Dado que su historia es la del Derecho y que la elaboración hacia su racionalidad tiene un marcado tinte jurídico (exterior, en oposición a lo moral), la doctrina citada, expresada en el aforismo "venire contra factum proprium non valet", puede ser una herramienta útil para operar con la noción de buena fe, máxime si la historia ha llevado la doctrina a un progresivo ocultamiento tras normas específicas $u$ otros institutos de cuño moderno que, paradójicamente, la pone al nivel en el que se debate la buena fe: lindando entre lo jurídico y lo moral.

El presente trabajo elucidará la doctrina de los actos propios con el propósito, en lo posible, de rescatarla para el Derecho civil peruano.

\section{RESEÑA HISTORICA DE LA DOCTRINA DE LOS ACTOS PROPIOS}

La noticia histórica suele darnos esa información que permite entender el presente cabalmente, en la medida que aclara conceptos 
desarrollados precisamente en el decurso histórico y que distingue lo actual de lo pretérito.

Casuístico y lógico, el Derecho romano es el punto de partida inevitable para comprender y distinguir la doctrina de los actos propios en su larga evolución histórica. Sin embargo, por los caracteres que acabamos de anotar, hemos de cuidar que cualquier aproximación a dicho ordenamiento no importe un internamiento clandestino de lo actual en lo pasado, porque por este camino encontraremos aquello que hemos introducido y no lo que esperamos encontrar. Así, por ejemplo, expresiones tales como "venire contra factum proprium" o "adversus factum suum quis venire non potest" no tienen con el derecho romano más vínculo que el lenguaje en el que se manifiestan. $\mathrm{Y}$ es que la casuística romana, recogida finalmente por Justiniano no generó la doctrina que estudiamos, pero sí aporta una serie de principios que informaron y dieron origen a su contenido. Comentar algunas normas estimamos que dará una imagen de la forma como aparece la materia.

En el Derecho romano estaba prohibido que un padre impugnara, a la muerte de su hija, la validez de un testamento otorgado por ella, "mancipada en derecho", alegando, contra su propio hecho (de haberla tenido como sui juris), que no la había emancipado según derecho (D.1.7.25.).

Esta norma se dictó debido a que, ante una pretensión como la señalada, la solución jurídica de la litis era claramente adversa a la validez del testamento (pues había sido emancipada sin observar las formalidades requeridas por el derecho) y, sin embargo, contrariaba la equidad que sólo se alegase la incapacidad jurídica $-y$, en consecuencia, el ejercicio actual de la patria potestad sobre la hijapara invalidar un testamento - que instituia herederos distintos del padre - una vez fallecida la hija y no mientras vivia; repugnaba aún más, si consideramos que en vida el padre reconoció de palabra y obra la condición de mater familias a la hija, lo cual hacía suponer que se conduciría en ese mismo sentido una vez extinta.

La razón que motivó la norma comentada fue, pues, la obtención de un resultado objetivamente inicuo, merced a la contradicción de la propia conducta previa en el contexto expuesto ( $C$ fr. Diez Picazo 1963: 22 y ss.). 
Otro caso pertinente es el que nos refiere el fragmento 11 del Digesto 8,3. Allí se recoge un precepto de Celso por el cual un concesionario de una servidumbre de paso no puede ser molestado en el ejercicio de su derecho - por ser éste más benigno- por los copropietarios que le han concedido el derecho, aun cuando no se halle perfecto el derecho de servidumbre debido a la falta de asentimiento de algunos de los dueños.

Aquí tenemos un caso de servidumbre cuya constitución no ha quedado concluida. En estricto derecho civil, el beneficiario de la servidumbre tendrá un título perfecto cuando todos los condóminos den su asentimiento; hasta entonces debíamos entender que no puede ejercitar el derecho de paso porque no tiene tal derechoy, esto, debido a la imperfección de su investidura.

La solución romana que comentamos difiere de la estricta respuesta civilista en que la falta de un título perfecto no es razón suficiente para que, en equidad, el propietario concedente se oponga al hecho del paso, cuando éste, precisamente, ya ha concedido respecto de sí el derecho a pasar.

Se colige de lo expuesto que sólo el dueño no concedente tiene expedita esa acción y, por otro lado, se aprecia nuevamente cómo el derecho romano opta por una solución "más benigna" (así reza el texto de Celso) para el concesionario sin derecho subjetivo -diríamos hoy- al vetar la acción de los propietarios contra la perturbación posesoria por ser inconciliable con la conducta anterior de los concedentes.

Un último - pero no el último- pasaje apropiado del Digesto, que extraemos a manera de resumen, es el que dice: "Nadie puede cambiar su propio designio en perjuicio de otro" (D.50.17.75). Este principio, que trasluce por su redacción la amplitud de un principio general del Derecho y, por ende, la posibilidad de una síntesis romana de varias normas, es, en realidad, una regulae juris: la expresión breve de un principio o fundamento de derecho empleado para resolver un caso concreto, o sea, es "la regla que se hace con arreglo al Derecho" (Paulo), pero no es el Derecho.

Debido a que se trata de una regla de derecho no tenemos la certeza sobre las circunstancias de su origen; los autores romanistas 
(Cfr. Diez Picazo 1963: 35) la remiten a otros pasajes de Papiniano, su autor, los cuales reproducen el elemento esencial señalado en casos anteriores: la idea de contradicción entre dos actos realizado por una misma persona.

Sin constituir en sí una doctrina, los textos romanos han servido de base para su posterior y paulatina estructuración. Así, volvemos a encontrar los pasajes del Digesto en la obra de los glosadores y comentadores.

Unos y otros han construido, entre los siglos XI y XIV, el corpus juris a partir del cual se elaboró, tiempo después, el derecho civil codificado, porque llevaron adelante el esfuerzo de racionalización y primera síntesis de los preceptos romanos, recurriendo a la metodología escolástica. La glosa, como primer fruto de la racionalidad, no se limitó a ser exegética sino que, superando las contradicciones manifiestas en los textos romanos, a partir de la tarea de interpretación y aclaración, nos lleva a los brocardos: reglas sintéticas, generales obtenidas - iinducidas? - de los textos romanos concordantes y discordantes, como si se trataran de los principios fundamentadores de la casuística romana.

Acursio, uno de los principales glosadores, se referirá a nuestro principio en su glosa "factum suum" del precepto del Digesto $1,7,25$ y en la "non posse" del D.8.3.11., pasajes ambos a los que hicimos mención líneas arriba. Sin embargo, la primera formulación como brocardo de la doctrina de los actos propios aparecerá antes en la obra de Azo titulada, en su expresión breve, "Brocardica"; allí se dice "venire contra factum proprim nilli conceditur".

Azo, ejercitando la técnica escolástica de las distinciones, establecerá que no se puede actuar contra el hecho propio si la ilegitimidad que facultara a enervarlo radicara en la inobservancia de presupuestos de eficacia, de formalidades o de concurrencia de voluntades necesarias. Como se advertirá, Azo apoya sus distinciones justamente en los textos romanos citados (Véase Diez Picazo 1963: 45 y ss.).

Siguiendo con el proceso de generalización, encontramos en Bartolo de Sassoferrato la distinción entre el factum proprium 
realizado secundum legem, praeter legem o contra legem, señalando que sólo el último es por naturaleza revocable. Baldo de Ubaldi, otro posglosador notable, señalará, por su parte, otras distinciones cuya poca claridad será, en el futuro, lo típico en esta materia (Diez Picazo 1963: 47).

No tendrá el aforismo "venire contra factum proprium..." nuevos aportes en los siglos siguientes, no obstante su profuso empleo. La escuela del derecho natural, por ejemplo, acogerá el aforismo sin proponer una elaboración doctrinal. Recién al comenzar este siglo aparece la obra del alemán Riezler, titulada como reza el aforismo, la cual inspirará el texto del español Luis Diez Picazo, que nos ha sustentado lo hasta aquí desarrollado.

La confusión y proximidad con otros institutos jurídicos, así como la existencia de otros preceptos romanos, directamente contradictorios, tornan imperativo el resolver la cuestión sobre su aplicabilidad. Baste indicar que se reconocen dos situaciones claras en las que es válido impugnar (el término alude a mucho más que el recurso a los medios procesales) los hechos propios. La primera es cuando la impugnación beneficia a un tercero o le evita un perjuicio (p.e.: el reconocimiento de un hijo negado reiteradamente); la segunda se verifica cuando el hecho propio es manifiestamente contrario a la ley, esto es, al decir de algunos, realizado contra una prohibición legal, $\mathbf{0}$, en expresión de otros, nulo por una razón de pública utilidad.

Precisamente, uno de los problemas centrales de la doctrina de los actos propios es su indeterminación dentro del Derecho. No aparece, por lo pronto, como una norma legislativa ni como una jurisprudencial. El Tribunal Supremo español, que tanto ha recurrido a ella para sustentar su aplicabilidad o inaplicabilidad, la denomina sucesivamente "doctrina", "principio de derecho", "constante normativa", "teoria", "principio general del Derecho" y "aforismo".

Si bien las alternativas son múltiples, podemos afirmar, en principio, que no estamos ante un principio general del Derecho. Existe una amplia gama de situaciones en las que, como hemos señalado, los hechos propios sí pueden ser válidamente impugnados por su autor. La idea constante que encontramos, sin embargo, subyaciendo a su aplicabilidad es la de la buena fe que debe poder 
guiar a los afectados con los actos propios. "Venire contra factum proprium" parece, pues, vinculado al principio general de la buena fe, el cual trataremos a fin de delimitar nuestro tema.

\section{INSERCION DE LA DOCTRINA DE LOS ACTOS PROPIOS EN EL PRINCIPIO GENERAL DE LA BUENA FE}

Durante el recorrido histórico anterior se ha constatado que la doctrina de los actos propios se originó en el afán de impedir que una respuesta ajustada al derecho sea, a la vez, la solución injusta para un easo concreto.

Lo inicuo de contradecir un acto propio estribaba en el perjuicio que se ocasionaría al que se sustentó en, o benefició con, el acto objeto de impugnación, quien se condujo creyendo en la validez del acto en mención y, o, confiando en la rectitud de conducta del ahora impugnante.

Ahora bien, establecer -o establecido- el sentido de justicia que distingue al aforismo "venire contra factum proprium" no implica, sin embargo, una respuesta clara a la pregunta sobre lo que en definitiva es, o significa, para el Derecho. Sobreentendido como ideaguía, por ejemplo en la jurisprudencia española, la doctrina discute si es una norma jurídica o un principio general del Derecho, descartando ambas posibilidades porque, en primer lugar, no aparece legislado en ningún cuerpo de derecho positivo ni puede afirmarse que sea una costumbre jurídica, no obstante la mención constante que, argumentalmente, se hace del aforismo en los tribunales españoles, por ejemplo $\left(^{*}\right)$. En segundo lugar, no parece tratarse de un principio general del Derecho, desde que es posible formular tantos casos en los que se puede actuar en contra del propio hecho como en los que no se debe. "Venire contra factum proprium" no puede, pues, ser subsumido en algunas de las categorías que organizan el sistema jurídico por lo que requiere de una delimitación especial.

(*) En el Perú, que sepamos, no ha habido desarrollo doctrinal alguno ni tampoco un usus fori que nos dé noticia sobre este tópico. 
El punto de partida de esta delimitación estimamos que se encuentra en el modo cómo la doctrina ha insertado el aforismo en el ámbito jurídico. La casuística romana y los brocardos medievales no nos proporcionan una guía explícita en este sentido; sin embargo, la moderna doctrina ubica nuestro tema dentro del principio general de la buena fe:

"Esta máxima [venire contra factum proprium] expresa de forma tan inmediata la esencia de la obligación de comportarse de acuerdo con la buena fe que a partir de ello se alumbra la totalidad del principio" (Wieacker 1977: 60).

La buena fe es entendida usualmente en dos sentidos; por uno, se trata de la honradez o rectitud que observa o cree tener quien realiza negocios jurídicos; por el otro, se refiere a la confianza que se deposita en la persona, de quien se deriva un derecho u obligación, en que se conducirá recta u honradamente según estándares más o menos prefijados. En el primer caso tenemos la teoría subjetiva o psicológica de la buena fe; en el segundo la objetiva o ética ( $C f r$. DiezPicazo en Wieacker 1977: 13; y M. Rubio 1987: 235).

Por la buena fe subjetiva se debe evaluar la intención que tuvo la persona para actuar y, del análisis de los móviles, determinar si se condujo honestamente. Con la buena fe objetiva no nos preguntamos por lo que ocurre en el fuero interno de las personas, en cada caso, sino que nos prefiguramos una conducta tipo, un modelo de conducta social, que nos sirva de medio de comparación de la conducta objeto de evaluación.

La doctrina distingue, por otra parte, la buena fe como un concepto técnico-jurídico que adquiere concreción en cada norma que la recoge, y el principio general de la buena fe que contiene una norma jurídica completa ("todas las personas deben comportarse de buena fe en sus relaciones recíprocas") y ya no un simple elemento complementario de normas jurídicas, como en el primer caso.

A veces, parecen confundirse los dos criterios de clasificación de la buena fe anotados. Así, Diez Picazo señala que: 
"si la buena fe, considerada objetivamente, en sí misma, es un modelo o un arquetipo de conducta social, hay una norma jurídica que impone a la persona el deber de comportarse de buena fe en el tráfico jurídico (...).

Esta norma, que impone un comportamiento de buena fe en la vida jurídica es un principio general del derecho". (1963: 139).

Sustentamos en el párrafo transcrito la confusión porque el principio general por el cual debemos comportarnos de acuerdo con la buena fe es perfectamente realizable tanto en una concepción objetiva de la buena fe como en la subjetiva. Si asumimos que el principio general de la buena fe nos impone conducirnos de acuerdo con ella, en un primer momento, y luego, en otro segundo, tenemos que establecer si una persona actúa de buena fe, recién en este último procederemos a escoger la vía por la que constataremos si hubo buena fe. Llegado a este punto, debemos recordar que la fe (fides) no alude al conocimiento que se tiene de las cosas sino a la intención puesta al hacerlas.

Así, pues, podemos inquirir por esta intención atendiendo a las circunstancias particulares que nos den noticia de lo ocurrido en el interior del hombre, o juzgar su conducta externamente, de acuerdo a parámetros o modelos preestablecidos y ello significará optar por la vía subjetiva o por la objetiva, respectivamente. En ambas maneras se trata de detectar si se ha cumplido con el deber de comportarse de acuerdo con la buena fe en los hechos y actos practicados. Por lo demás, la alternativa no reposa en la decisión del intérprete únicamente sino que puede ser, también, una elección imperativa del legislador, en atención a la naturaleza de las circunstancias que pretende poner bajo el amparo normativo.

No corresponde a este trabajo elucidar la naturaleza última de la buena fe. Lo que sí asumimos como claramente determinado es que "todo el ordenamiento jurídico debe ser interpretado en armonía con el principio general [de la buena fe]" (Diez Picazo 1963: 139), y esto supone que:

a) los deberes de conducta por observar en las relaciones jurídicas 
se extiendan más allá de lo estrictamente acordado, en concordancia con la buena fe, si se coadyuva a la obtención del fin previsto;

b) el ejercicio de los derechos subjetivos no exceda la finalidad de la relación o la función económica o social ni la lealtad que se espera se guarde, en el ejercicio del derecho subjetivo (confianza), de acuerdo con las circunstancias particulares; $y$

c) no se defraude la expectativa generada en una persona, a partir de la propia conducta, respecto a los hechos propios futuros ("comportamiento coherente"), lo cual involucra la aparientia juris pero no se agota en ésta. (Cfr. Puig Brutau 1951: 103).

En este último acápite, reconocido ampliamente por la doctrina, encontramos el punto de amarre entre el principio general de la buena fe y el aforismo "venire contra factum proprium". Lo siguiente es precisar si la doctrina de los actos propios corresponde a una visión objetiva o subjetiva de la buena fe. Provisionalmente, y por lo visto hasta este momento, podemos afirmar que la imposibilidad de venir contra un hecho propio responde a una perspectiva objetiva de la buena fe. Confirmar o negar lo aquí afirmado será la tarea inmediata.

\section{DELIMITACION FINAL DE LA DOCTRINA DE LOS ACTOS PROPIOS}

Circunscrita al ámbito de la buena fe, y dentro de él a la exigencia de un comportamiento coherente, la doctrina de los actos propios puede parecer clara en sí misma, pero aún es necesario deslindar semejanzas o yuxtaposiciones con otros institutos jurídicos.

Lo primero a tener presente para distinguir el "venire contra factum proprium" es que no procede de la fuerza vinculante generada por una declaración de voluntad. En efecto, celebrado un negocio jurídico, las partes intervinientes deben someterse a la regla de conducta estipulada en él; pueden ejercer los derechos que el negocio les confiere, pero no revocarlo ni inobservarlo unilateralmente. Incluso puede suceder que la declaración de voluntad tenga el carácter de tácita o que contenga la renuncia de un derecho y, aun más, que se 
inscriba dentro de una conducta social típica. En todos estos casos se ha creido encontrar el lugar natural de la doctrina subestudio. Se ha alegado que nadie puede negar el sentido que la colectividad atribuye a una "conducta social tipo", o la invalidez de una reasunción del derecho renunciado, ni que ante hechos concluyentes no estemos ante una declaración de voluntad tácita, porque en todos estos casos sería venir contra los actos propios.

Empero, la razón fundamental en todas esas situaciones no es que atenta contra la buena fe sino que se resta eficacia a la propia voluntad $o$ al acuerdo de voluntades como generadores de derechos y obligaciones. Ciertamente, el contradecir la propia voluntad es formalmente un "venire contra factum proprium", pero si esta doctrina se agotara en los límites así descritos ella no tendría ninguna relevancia por sí misma, desde que el acuerdo de voluntades y la declaración de voluntad, en general, vinculan a quienes la emiten. El consentimiento ha adquirido, finalmente, con el individualismo y el liberalismo, esa fuerza y vigor propios de la ley -ahora en franca morigeración-, constituyéndose en razón suficiente de la existencia de los negocios jurídicos en general.

Por todo lo dicho, el aforismo que nos ocupa, en realidad, apunta a un tipo de situaciones en las que siendo legal, o ajustada a derecho, la común interpretación o aplicación de una declaración de voluntad negocial, ésta provee una acción u omisión injusta, en tanto esa acción u omisión contradice la conducta previamente observada y las expectativas que, de buena fe, se habían generado a partir de ella.

Un caso particularmente ejemplar es el de la renuncia de derechos. Usualmente se interpreta que la doctrina de los actos propios reposa en la manifestación de voluntad por la que se renuncia a ciertos derechos; sin embargo, esto no es exacto porque, en primer lugar, la renuncia de derechos supone una declaración de voluntad en tal sentido, lo cual no se da en el "venir contra un acto propio", pues no sólo prescinde de la declaración de voluntad sino que puede producirse contra la voluntad de quien está prohibido de contradecir su conducta. En segundo lugar, la renuncia de derechos importa la extinción total del poder jurídico que emana del derecho subjetivo, mientras que el factum proprium sólo declara inadmisible el ejercicio del derecho en determinadas circunstancias porque comportan un 
resultado inesperado en términos de buena fe. No extingue el derecho, únicamente lo limita por ser contrario, en este caso, a la buena fe.

Finalmente, conviene distinguir la doctrina de los actos propios de la exceptio doli. Esta excepción tiende a invalidar la pretensión (exceptio doli specialis) y la acción (exceptio doli generalis) intencionalmente contrarias a la buena fe; de estos se derivaba que era opuesto a la buena fe hacer valer un derecho o ejercitar una acción discrepantes de la conducta previa; empero debe anotarse que la exceptio doli invalida la pretensión (o la acción) por la intención que la impulsa y no porque contradiga la conducta previa. La excepción de dolo es perfectamente deducible ante la conducta coherentemente dolosa.

Establecido lo que no es el aforismo "venire contra factum proprium", aprovecharemos de la definición dada por Enneccerus para aproximarnos a una conceptualización definitiva de la doctrina estudiada. Enneccerus afirma:

"A nadie le es lícito hacer valer un derecho en contradicción con su anterior conducta, cuando esta conducta, interpretada objetivamente según la ley, según las buenas costumbres o según la buena fe, justifica la conclusión de que no se hará valer el derecho, o cuando el ejercicio posterior choca contra la ley, las buenas costumbres o la buena fe (prohibición del venire contra factum proprium, stoppel en el derecho inglês)" (1950: I - 2, 495).

En primer lugar, tenemos un mandato negativo: una prohibición. Cierto es que todo mandato negativo puede ser formulado positivamente ("respetar la vida", en lugar de "no matar") y que, en nuestro caso, la expresión positiva sería un mandato de observar una conducta coherente; sin embargo, la prohibición tiene dos matices no advertibles fácilmente en su sentido positivo. La prohibición puede implicar un "deber negativo", esto es, no actuar de un modo determinado, o un "limite al derecho subjetivo", es decir, no poder actuar de un modo determinado. 
La distinción sutil se apoya en que la primera implicación propone una conducta negativa pura y simple (la típica obligación de no.hacer), mientras que la segunda parte de un conjunto de conductas posibles (derechos subjetivos) limitadas por ciertos modos o ante ciertas circunstancias.

Diez Picazo aporta a esta distinción los diferentes efectos que se generan. Si se incumple un deber jurídico, dice el autor español, se incurre en responsabilidad y se hace pasible de sanción (p.e.: una indemnización); en cambio, si se extralimita en el ejercicio de un derecho subjetivo el acto se torna ineficaz o inválido. Diez Picazo sostiene que ambas medidas pueden darse a la vez, pero "es claro que la prohibición de ir contra los propios actos constituye un límite de los derechos subjetivos" (1963: 186).

La síntesis teórica esbozada por el autor citado coincide con la tradición doctrinal reseñada hasta ahora porque, debemos recordar, la prohibición no está dirigida en general a restringir tal o cual conducta, sino que se trata de impedir que el ejercicio de cualquier derecho contra factum proprium, en determinadas circunstancias, sea admisible o válido.

El contenido de la prohibición, cuya naturaleza acabamos de ver, merece una nota conclusiva. El hecho de venir contra un acto propio debe entenderse siempre como el ejercicio de un derecho positivamente reconocido. Toda la doctrina se referirá siempre a un derecho que se tiene y ejerce contra lo supuesto a partir de la conducta previa; no se trata de un hecho opuesto a otros anteriores, porque entonces habría que determinar la licitud o ilicitud del mismo, en atención a las circunstancias que le preceden y rodean, y no generaría, por tanto, ninguna expectativa. Así, pues, no está en discusión si se tiene o no el derecho que se pretende hacer valer.

Ahora bien, Enneccerus señala inmediatamente que la conducta es contraria cuando nos provee de la creencia de que no se hará valer el derecho. Sin embargo, indica que la creencia proviene de la interpretación objetiva de la ley, las buenas costumbres o la buena fe, todo lo cual consideramos excesivo. ¿De qué manera la interpretación objetiva de la ley puede justificar la conclusión de que no se hará valer el derecho? Si la ley prohibiese el ejercicio del derecho en un 
momento en particular, 0 ante la presencia de ciertos elementos, ya no estaríamos, en ese preciso momento, ante el ejercicio de un derecho. Este se hallaría suspendido por lo menos y entonces saldríamos de la esfera de la doctrina pues, como indicáramos, supone el ejercicio de un derecho.

Téngase en cuenta que lo afirmado en el párrafo que antecede no sólo es pertinente para el caso de la prohibición expresa sino que lo es, también, para todos aquellos resultados de la interpretación que concluyan en que la ley no admite el ejercicio del derecho subjetivo.

La misma objeción que hemos formulado respecto de la ley es aplicable a las buenas costumbres. Si bien éstas vinculan lo jurídico con la moral -objetiva y exterior, por cierto- no dejan de ser, ante todo, costumbres jurídicas y, por tanto, normas imperativas (una vez probada su existencia). Por ello cabe repetir la pregunta hecha respecto de la ley: ¿Cómo puede tenerse, al mismo tiempo, un derecho consuetudinario y la amenaza de la nulidad sobre su ejercicio, por contrariar las buenas costumbres?

En nuestra opinión, solamente el principio de la buena fe puede respaldar lógica y lícitamente la limitación al ejercicio de un derecho subjetivo. Indudablemente, la buena fe no se agota en la limitación anotada, también es causa de exoneración o atenuación de la culpabilidad en un acto formalmente ilícito, y es fuente creadora de deberes especiales de conducta a partir, y más allá, de lo expresamente estipulado (Wieacker 1977: 19).

"Venire contra factum proprium", por su formulación en sentido negativo, coincide plenamente con la buena fe-causa de limitación; en cambio, no es la doctrina una causal de exoneración o atenuación de la culpa en quien ejerce su derecho subjetivo, por un simple juicio de identidad: no se puede actuar de buena fe contra la conducta generada de buena fe.

La buena fe-causa de exoneración de la culpa, por otro lado, sí beneficia al eventual perjudicado con el acto contrario al propio porque la exoneración que puede oponer aquél nace de la buena fe atribuida al tenedor del derecho subjetivo, en el sentido de que no ejercería el derecho. 
En resumen, la doctrina de los actos propios contiene un criterio de aplicación de la buena fe objetiva que puede oponerse a la posición contraria, pero que no puede ejercerse para sí mismo. La presencia de este criterio en la normatividad peruana será lo que nos ocupará en el capítulo final.

\section{LA DOCTRINA DE LOS ACTOS PROPIOS EN LA LEGISLACION CIVIL PERUANA}

Elucidada en alguna medida la doctrina de los actos propios, es propicio adentrarnos en la normatividad a fin de detectar, de un lado, las normas que han recogido en sus hipótesis casos que la doctrina habría resuelto sin necesidad del amparo legal y, de otro lado, los núcleos temáticos en los cuales es factible recurrir al aforismo como fundamento para enervar el ejercicio de un derecho no obstante -precisamente-el silencio legislativo. No creemos que los resultados sean completos pero sí darán una idea de la presencia real de la doctrina, mayor de la que estimábamos al comenzar, y de sus posibilidades argumentativas hacia el futuro.

Con relación a las normas que recogen la doctrina podemos citar, en primer lugar, el artículo 226 del Código Civil (C.C.), que dice:

\footnotetext{
"Artículo 226.- La incapacidad de una de las partes no puede ser invocada por la otra en su propio beneficio, salvo cuando es indivisible el objeto del derecho de la obligación común".
}

El hecho propio en esta norma es el acto jurídico celebrado; la expectativa generada es la usual entre quienes lo celebran: el querer crear, regular, modificar o extinguir relaciones juridicas. Legalmente, el interviniente capaz, de acuerdo a otra hipótesis normativa, tiene derecho a pedir la nulidad del acto (art. 221 , inc. $1^{\circ}$ del C.C.) no obstante ser contrario al fin proyectado; sin embargo, si con la nulidad se pretende obtener un beneficio, que no lograría ejecutando el acto y que, evidentemente, la otra parte no tendría entre sus expectativas, entonces estará vulnerando la buena fe puesta por el interviniente incapaz en querer el fin propuesto. 
Similar esquema conceptual podemos encontrar en el art. 229 del C.C. Sin embargo, la prohibición de pedir la nulidad está dispuesta contra el propio incapaz porque no se trata de una aplicación del "venire contra factum proprium" sino de la exceptio doli. El punto de partida de la prohibición no es la expectativa nacida de la buena fe sino la mala fe con la que se ha actuado, lo cual, coincidentemente, impide ir contra el propio acto.

Otro caso de aplicación de la prohibición de ir contra el propio acto, pero con resultado distinto, es el contemplado en el art. $231 \mathrm{del}$ C.C.:

"Artículo 231.- El acto queda también confirmado si la parte a quien correspondía la acción de anulación, conociendo la causal, lo hubiese ejecutado en forma total o parcial, o si existen hechos que inequívocamente pongan de manifiesto la intención de renunciar a la acción de anulabilidad".

Allí encontramos una primera norma sobre la renuncia a la acción de anulabilidad del acto - y consiguiente confirmaciónverificada en la hipótesis de que se ejecute total o parcialmente; ésta no interesa a nuestra doctrina desde que ya hay una manifestación de voluntad tácita. La segunda hipótesis del artículo creemos que sí es pertinente porque no hay una renuncia sino una expectativa generada por "hecho inequivocos" que han puesto de manifiesto la "intención" de renunciar. La intención es una determinación de la voluntad en orden a un fin, es decir, un fenómeno interno del ser humano que se verifica inmediatamente antes del acto. Ahora bien, la solución legal difiere de la doctrina de los actos propios en que no se limita a prohibir la conducta contraria - la anulación - a la esperada a partir de los "hechos inequívocos", sino que la hace imposible permanentemente por la confirmación del acto que esa expectativa generó.

El art. 194 del C.C. nos remite a la teoría de la apariencia como justificante para prohibir el hecho de ir contra un acto propio:

"Artículo 194.- La simulación no puede ser 
opuesta por las partes ni por los terceros perjudicados a quien de buena fe y a título oneroso haya adquirido derechos de titular aparente".

En la teoría de la apariencia se discute si esta conducta aparente es realmente el hecho propio cuya coherencia debe guardarse. Por sí mismo creemos que no, pero cuando por el cuadro de circunstancias se advierte que ha dado origen a una esperanza sobre la actuación futura (aspiración a ejercer la titularidad de un derecho, la onerosidad de la aspiración), entonces la prohibición de contravenir el hecho propio resulta justa en atención a la buena fe depositada en los simuladores. dice:

Hipótesis similar es la contenida en el art. 285 del C.C., que "Artículo 285.- El matrimonio invalidado produce los efectos de un matrimonio válido disuelto por divorcio, frente a los terceros que hubieran actuado de buena fe".

En este caso, la apariencia es reemplazada por la ficción legal de atribuir validez al matrimonio anulado sólo en cuanto se refiere a los efectos frente a terceros que actuaron de buena fe. La "apariencia de validez" generó, una vez más, una expectativa en los terceros debido, precisamente, a que creyeron de buena fe en el acto. Esta buena fe impedirá a los que estuvieron "aparentemente" casados impugnar la validez de los actos celebrados con estos terceros, arguyendo la nulidad del matrimonio.

Pasando a la materia obligacional encontramos dos hipótesis normativas similares:

"Artículo 1275.- No hay repetición de lo pagado en virtud de una deuda prescrita, o para cumplir deberes morales o de solidaridad social o para obtener un fin inmoral o ilícito. (...)"; y

"Artículo 1943.- El juego y la apuesta no autorizados son aquellos que tienen carácter 
lucrativo, sin estar prohibidos por la ley, y no otorgan acción para reclamar por su resultado. El que paga voluntariamente una deuda emanada del juego y la apuesta no autorizados, no puede solicitar su repetición, salvo que haya mediado dolo en la obtención de la ganancia o que el repitente sea incapaz".

Ambos textos legales nos proponen como hecho propio el pago voluntario y como acto contrario al hecho propio la repetición de lo pagado, el cual, de acuerdo a dichas normas, está prohibido. Hasta aquí la similaridad. Aplicando la doctrina desarrollada sólo encontramos la esperanza de una conducta coherente como justificante de la prohibición en los deberes morales y de solidaridad social. La buena fe que motiva esperar la coherencia proviene de que el cumplimiento de tales obligaciones no tiene su sustento en norma legal alguna; luego, el "pago" sería, en realidad, una liberalidad en el plano jurídico. Sin embargo, esta reflexión nos lleva a la conclusión de que la repetición en ningún momento es un derecho, con lo que podríamos afirmar que no es aplicable la doctrina de los actos propios; pero, por otra parte, si en lugar de entender el pago como una liberalidad le asignamos la naturaleza de pago indebido entonces sí tendría derecho a la restitución quien pagó y, en consecuencia, la norma que comentamos sería la expresión legal de una solución de justicia al ampararse la buena fe con arreglo a la doctrina de los actos propios.

Igual raciocinio podríamos hacer respecto de las otras hipótesis contenidas en las normas legales citadas. Empero, es claro que el derecho a cobrar una deuda prescrita subsistía - la prescripción mata la acción pero no el derecho-; que se sanciona lo pagado con propósitos inmorales o ilícitos; y que es propio de la naturaleza del juego y la apuesta el generar créditos ineficaces, aun cuando nuestra legislación distingue entre autorizados, no autorizados y prohibidos, reconociendo eficacia a los provenientes de los autorizados.

Orientados por la doctrina de los actos propios, creemos encontrar, finalmente fuera de los ejemplos anotados, tres núcleos temáticos en los que parece posible el desarrollo de la doctrina y uno adicional que mencionamos con serias reservas. 
Este último es el de la prescripción adquisitiva de dominio. La institución podría ser un terreno fértil porque estaríamos ante una conducta omisiva (la del propietario original) y otra activa (la del poseedor) que, tolerada por el propietario, darian lugar a las condiciones requeridas por la doctrina de los actos propios y, en consecuencia, al impedimento del propietario de recuperarla. Sin embargo, nuestras serias reservas nacen de los caracteres de exclusividad e imprescriptibilidad de la acción reivindicatoria que adornan todavía a la propiedad. Por esto es indispensable recurrir aún a la ley para convertir en derecho una situación de hecho en materia de propiedad; no bastan los actos propios del dueño original, ni siquiera si se trata de hechos inequívocos que manifiesten una especie de renuncia al derecho a reivindicar.

Las otras áreas donde sí, creemos, podría expandirse la doctrina subestudio son la de la validez del acto jurídico, la del legítimo interés y la de la resolución y rescisión de los contratos. Sobre la primera hemos dado ya algunos ejemplos pero estimamos, sin pretender certeza absoluta, que es posible extender los efectos de la doctrina a las otras causales de anulación.

El interés legítimo, amparado legislativamente, da a las personas la facultad de ejercitar tal o cual acción. Ante este tipo de circunstancias creemos que puede abrirse la puerta a la excepción de la acción si el interesado realiza actos contrarios al ejercicio que es conforme al interés, a fin de producir la convicción de que no hará valer el derecho en el futuro. Ejemplos particularmente idóneos podemos extraer de los artículos 15 (sobre el derecho a la propia imagen), 185 (sobre el cumplimiento del cargo), 351 (sobre la reparación del daño moral en el divorcio) y 1316 (respecto del acreedor interesado en el cumplimiento de la obligación).

Un último núcleo es el que nos proporciona el art. 1372 del C.C., al disponer que la resolución y la rescisión de los contratos no perjudicarán los derechos de los terceros adquiridos de buena fe. El contratar es un "hecho propio" que puede ser objeto de contradicción por alguna de las partes a fin de que se resuelva o rescinda sin que necesariamente exista mala fe. Oponer la buena fe para evitar un perjuicio corresponde con el esquema de la doctrina que hemos estudiado. 
La materia trabajada, como todas aquellas vinculadas a estándares jurídicos, no nos propone un contenido preciso e invariable, sino un criterio para identificar, en cada caso, si es legítima o justa la pretensión. Es por ello que la doctrina de los actos propios ha tenido en los tiempos modernos un desarrollo fundamentalmente jurisprudencial y se nos presenta, procesalmente, antes que como una acción, con la aptitud para hacerle frente a la pretensión: es decir, como una excepción. Los estándares jurídicos son conceptos flexibles, dentro del rigor legislativo de las normas imperativas, que "dejan al juez o funcionario una amplia libertad de apreciación" (Du Pasquier 1950: 112); siendo la buena fe uno de estos estándares, "venire contra factum proprium", a su vez, será una directiva objetiva, que podrá seguir el intérprete, juez o funcionario, para encauzar el estándar buena fe y oponerlo, por la vía de la excepción, a la pretensión injusta.

Lo que proponemos, a modo de reflexión final, es que, si bien el Derecho requiere de conceptos flexibles para regular la conducta humana (nunca exclusivamente racional), es conveniente que se den pautas objetivas, no al nivel de las normas abstractas, sino al de los criterios de apreciación de los casos concretos. La injusticia del rigorismo legislativo obligó a recurrir a los estándares en buena medida; sin embargo, dejar la apreciación de la conducta personal al arbitrio únicamente, i.e., al sentimiento o al estado de ánimo, nos parece poco científico para el Derecho y poco justo. Estimamos que los elementos jurídicamente relevantes en la conducta social no deben ser reducidos a la manera de lo hecho con nuestras normas abstractas. Lo relevante está también en las circunstancias singulares de cada caso y los estándares son una prueba de ello. Temas como el tratado aquí constituyen medios óptimos para llenar esos vacíos interpretativos y, quizá, legislativos. 


\section{BIBLIOGRAFIA}

DIEZ-PICAZO, Luis

La doctrina de los actos propios. Barcelona, Bosch. 1963.

DU PASQUIER, Claude

Introducción a la Teoría General del Derecho y la Filosofía Jurídica. Lima. Lib. Internacional del Perú. 1950.

ENNECCERUS, Ludwig y NIPPERDEY, Hans

Tratado de Derecho Civil, Derecho Civil, Parte General. Barcelona, Bosch. Tomo I, vol. 2. 1950.

PUIG BRUTAU, José

Estudios de Derecho Comparado. La doctrina de los actos propios. Barcelona. Ariel. 1951.

RUBIO, Marcial

Prescripción, Caducidad y otros conceptos en el nuevo Código Civil. Ed. Cuzco, Lima. 1987.

WIEACKER, Franz

El principio general de la buena fe. Madrid. Civitas. 1977. 